\title{
Experimental investigation on Thermal Performance of Copper with Aluminium Based Finned Heat sinks for Electronics Cooling System
}

\author{
${ }^{1}$ Arulmurugan L, ${ }^{2}$ Dr.llangkumaran $\mathrm{M}$ \\ ${ }^{1}$ Assistant Professor, Department of Mechatronics Engineering,K S Rangasamy College of Technology, \\ Tiruchengode, India. \\ E-mail ID: arulmurugan83@gmail.com \\ ${ }^{2}$ Professor and Head, Department of Mechatronics Engineering, K S Rangasamy College of Technology, \\ Tiruchengode, India. \\ E-mail ID: maniilankumaran@gmail.com
}

\begin{abstract}
An Experimental investigation on thermal performance of copper with aluminium based finned heat sinks for electronics cooling system was studied. The heat sinks have different material proportions containing major constituent of aluminium and minor constituent of copper. Considered with straight finned heat sink for the experiments for its easiness in fabrication and efficient heat transfer properties. The observational results for aluminium with copper alloy are compared with pure aluminium heat sink. Heat sink geometry, fin pitch and its height were taken from the commercially available heat sinks. In this research work best heat sink geometry is chosen and cooked up with different volume of copper added with aluminium. Selected four different spots of heat sinks and the temperature raising characteristics were measured for natural convection. Also the temperature is raised to a fixed temperature and the temperature lowering characteristics were measured in forced convection as the air circulation takes more heat to keep the heat sink temperature within the desired level.
\end{abstract}

\section{Indexing terms/Keywords}

Heat Sink, Convection, Aluminium, Copper, Electronics cooling system.

\section{INTRODUCTION}

The heat sinks are designed to solve the heat problems faced by high performance electronics systems. This is a traditional method to dissipate unwanted heat generated in the system. A computers CPU performs millions of computations every second. As the process continues to work, it starts to generate heat. If the heat is not kept under desired level, the processor could overheat and creates a chance for CPU damage. Different methods for cooling the electronics chips were proposed, use of thermo-electric coolers [1], two phase flow heat transfer with R-134 [2], the use of $\mathrm{R}-134$ provides a very effective heat transfer when compared to that of the conventional heat transfer rates, $\mathrm{R}-134$ is the most commonly used refrigerant having good heat transfer characters. but still it is a costly method of cooling and cannot be applied to a common and MEMS electronics devices, Flow boiling heat transfer of water in micro channel heat sink[3], two phase thermal transport in micro gap channels [4], the system used a cooling medium that changes its phase when the temperature difference occurs as in the refrigeration process, influence of surface roughness on natural convection above a horizontal plate, that analyzed an aluminium plain plate for the convective heat transfer, that prove that the more rough surface increases the area of contact of the plate with the air, the optimum rough surface would produce effective cooling, also it affects the heat flux flow directions that affects the heat transfer to air[5-9]. The conventional air-cooled cooling system uses forced convection system using a simple geometry having optimum efficiency, heat transfer characteristics [10]. Among other heat sinks parallel plate finned heat sinks are widely used for its own advantages in fabrication and cost optimization. Also it is having the advantage of independent of direction of fluid flow. Recently, Kim et al (11) exposed that the effective heat sink type among plate-fin furthermore pin-fin heat sinks might be firm depending on the propelling power and heat sink length. It is found that at low Reynolds numbers friction factors are reformed for intermediary size tubes. This has a dynamic allegation for micro scale pin fin heat sinks.

In addition to the above research activities, there has been a new attempt to combine the advantages of plate-fin and pin-fin heat sinks. The thermal resistance have a considerable effect on the heat sink. The total thermal resistance $\left(R_{\text {tot }}\right)$ can be expressed as the sum of three components that account for conduction through the silicon substrate excluding the fin region $\left(R_{\text {cond }}\right)$, convection to the flow $\left(R_{\text {conv }}\right)$, and thermal resistance due to an increase in the flow temperature as it flows through the fins and absorbs heat $\left(R_{\text {heat }}\right)$. Since the substrate thickness is usually small $(<500 \mu m)$ and the thermal conductivity of silicon is large $\left(150 \mathrm{~W} \mathrm{~m} \mathrm{~m}^{-10} \mathrm{C}\right), \mathrm{R}_{\mathrm{cond}}$ is usually very small and for most practical purposes can be neglected. Using a simple energy balance $R_{\text {heat }}$ can be expressed as:

$$
R_{\text {heat }}=1 / \mathrm{mc}_{\mathrm{p}}
$$

Similarly, $\mathrm{R}_{\text {conv }}$ can be expressed as

$$
\mathrm{R}_{\text {conv }}=1 / \mathrm{hA}_{\mathrm{t}}
$$

Where $A_{t}$ is the total effective heat transfer area, which can be expressed as follows:

$$
A_{t}=A_{b}+\eta A_{\text {fin }}
$$

Where $A b$ is the base area, Afin the surface area of the fins, and $\eta$ the fin efficiency. 


\section{COMPUTATIONAL FLUID DYNAMIC ANALYSIS}

Heat sink used in the CFD analysis part is modeled with SOLID WORKS 2010 modeling software and Used Star $\mathrm{CCM}+$ for CFD analysis to perform. A real time heat sink used in modeled with the same proportion of the heat sink used in the experimental study. The high temperature input is taken as $100 \mathrm{~W}$, which will be the maximum heat energy dissipated by a high speed microprocessor. The mesh created by Star CCM+ CFD software is shown in the figure 1. An analysis done for free and natural convection processes.

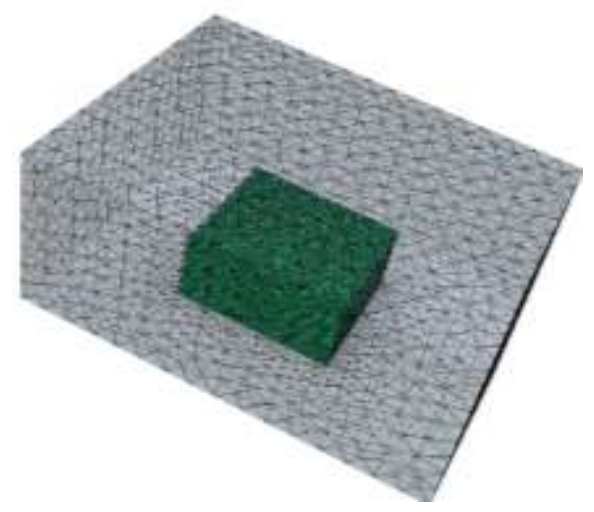

Fig 1 : Mesh created in Star CCM+

The geometry created for analysis is same as that of dimensions of the heat sink used in the real time experimental heat sink used. The geometrical dimensions of length $80 \mathrm{~mm}$, breath $60 \mathrm{~mm}$, height $30 \mathrm{~mm}$ and the fin thickness of $4 \mathrm{~mm}$ is used. The geometry is constrained with an external wall and letting the fluid at the inlet wall to outlet wall. The result of CFD software between natural and free convection shows considerable difference. The figure shows the constrains created for the analysis in Star $\mathrm{CCM}$, used with standard material properties of aluminium and copper as the input parameter and the fluid flow rate is set as 35 CFM which is the maximum fluid flow rate that can be created with a real time microprocessor heat sink fan.
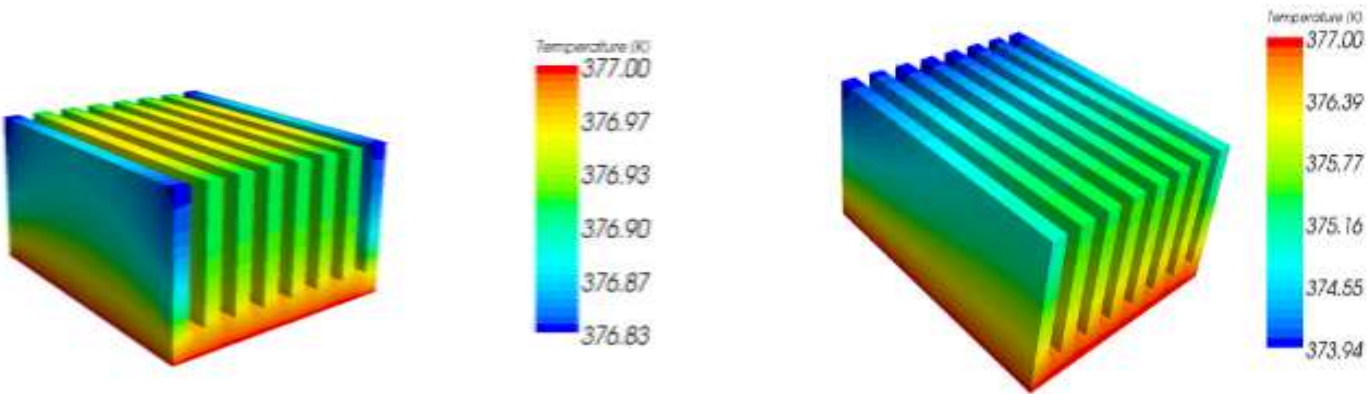

Fig 2 : Heat Transfer in Natural and Forced Convection

Since the cooler fan supplies with a lower temperature air into the fins of the heat sink, it removes the heat supplied into the heat sink at the lower temperature. The figure 2 shows that under natural convection this heat sink removes 80 Watts of heat energy at a higher temperature of $82^{\circ} \mathrm{C}$ and the same 80 Watts of heat energy is removed at much lower temperatures of $54^{\circ} \mathrm{C}$. This proves that the heat transfer achieved at with natural convections at a higher temperature level can be achieved even at a lower temperature by just allowing the air to pass through the surface area where the heat is being transferred to the air. Also the heat transfer characteristics differs in a significant way that the convection rate will be even throughout the area of the heat sink, but in case of forced convection the heat transfer rate will be high at the air entrance point and reduces at the exit point of air. 


\section{EXPERIMENTAL SETUP AND PROCEDURE}

This experimental setup is a smaller domain in order to simplify the experiments. The experimental setup is arranged with an electrical heater that replaces the position of processor in a real-time setup. The size of heater is $65 \times 85 \mathrm{~mm}$ which is 5 $\mathrm{mm}$ larger than the size of heat sink, it is marked with a tiny scratch over it to ensure the right location of the heat sink to be placed on it. It is supplied with 220V AC power supply, so that it can generate a heat of 100 Watts. The heater is fixed with heat sink using a anabond compound with thermal conductivity of $0.437 \mathrm{~W} / \mathrm{m}^{\circ} \mathrm{C}$ and wake field thermal compound with thermal conductivity of $0.735 \mathrm{~W} / \mathrm{m}^{\circ} \mathrm{C}$ is used as a mediator between heat sink and the heater, the application of wake field thermal compound ensure proper contact between heat sink and the heater surface. The system is placed with a commercially available blower fan to create a forced convection.

\section{T. - Thermocouple}

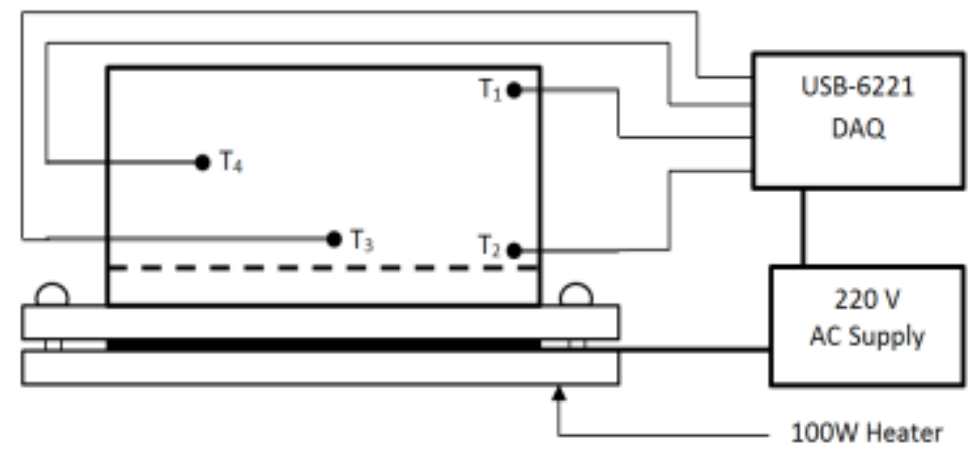

Fig 3 : Block Diagram of Experimental setup

The area occupied by the resistance coil is lower than that of the area occupied by the heat sink over the heater, so that the heating area completely covers the heat sink placed over it, so that the total heat energy output from heat heater will be transferred to the heat sink. Eight K-type thermocouple is paced at different places of the heat sink and temperature raise at four different places are considered and others are used as reference, since those points are symmetric about the axis of the heat sink geometry. The first thermocouple is placed at the top corner left side to the axis of the geometry, the second thermocouple is placed at bottom lower corner right side to the axis of the geometry and the third thermocouple is placed at the exact center of the heat sink and the fourth point for locating the thermocouple is fixed at $20 \mathrm{~mm}$ behind T3 and $10 \mathrm{~mm}$ from the bottom of the heat sink. Since the setup is placed at a open space, the atmospheric temperature is the temperature of air blown to the heat sink for forced convection experiments. In these experiments other external heat sources or not considered in order to simplify the experiments. The flow rate of the air for forced convection is maintained at a constant level by assuring the suction and delivery fan speed. The volume flow rate of the system is maintained at 35 CFM. The saturation temperature was recorded when the system maintains the temperature difference with in $\pm 1^{\circ} \mathrm{C}$ for a duration of 10 minutes. The temperatures are recorded and used to calculate the heat transfer rate of the heat sink

\section{DATA ACQUISITION SYSTEM}

The data acquisition system is responsible for the accuracy and reliability of the experimental readings. The parameter to be measured is temperature will not cross beyond $200^{\circ} \mathrm{C}$ and will not enter below $20^{\circ} \mathrm{C}$ level. For the data acquisition the experimental setup is interface with USB-6221 DAQ card. USB-6221 is a data acquisition card form national instruments having 15 analog and digital input ports and 3 analog and digital output ports. The K-type thermocouple is used in experimental setup; the thermocouples are directly interfaced with the DAQ card at the analog input ports ai5, ai6, ai7 and ai8. For data logging labview 2011 is used to interface the DAQ card with the computer system. Labview 2011 has pre-loaded calibration settings for K-type thermocouple, with a temperature compensation of $25^{\circ} \mathrm{C}$. Hence no external calibration is required for K-Type thermocouple when interfaced with USB-6221 and Labview2011.

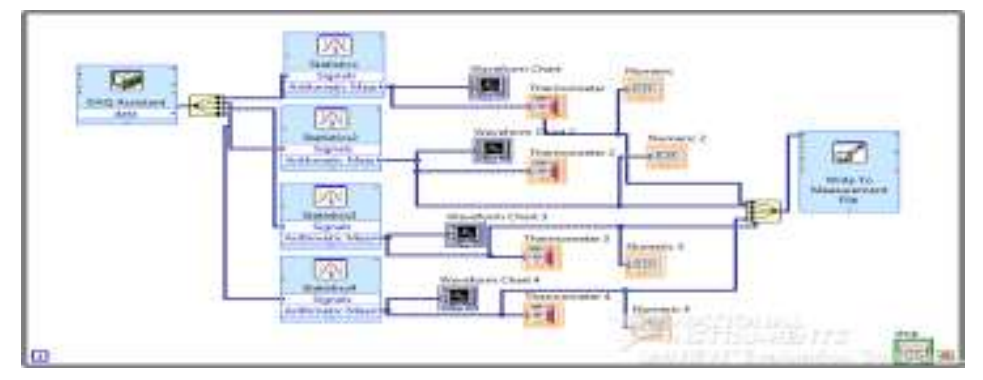

Fig 4 : LabVIEW Panel Block Diagram

4584 | $\mathrm{P}$ a g e 
The figure 4 shows the back panel block diagram of the labview system. The back panel uses with the tools of DAQ Assist that fetches the data sent by the DAQ card and brings in to the computer for data manipulation, since the DAQ brings in data at a frequency $100 \mathrm{~Hz}$, the arithmetic mean reduce it into $10 \mathrm{~Hz}$ by providing the arithmetic mean of every 10 values at the output. The signal splitter is used to split the data from four input channels. A graph tool along with a thermocouple and numerical display tool is placed to display the temperature raise characteristics and a temperature at a particular time. A signal merge tool is used to merge the signal so that the data from DAQ can be logged into a single Excel File with the help of Write to measurement file tool in the labview system. Since the data Acquisition takes place in a continues loop, the entire circuitry is placed inside a while loop. Placing the Write to measurement file tool outside the while loop will create a new file for every iterations for the readings to log. The function of thermocouple tool and the integer display tool is for the easy understanding and verification of the system, whether the experimental setup is performing with desired values.

\section{RESULTS AND DISCUSSIONS}

The graph shows the temperature raise characteristics of the heat sink with various copper mixture ratios. Since the airflow rate is very low the heat flow around the heat sink will be low, also the air circulating around the heat sink area. Also because of the lower temperature raise it takes about 10 minutes to 15 minutes to reach the saturation level after which it reaches the saturation level and starts maintaining at that level with one or two degree fluctuations. If the system maintains with this least fluctuation for about 10 minutes then it is considered that the system reaches its saturation level.

\subsection{Natural convection}
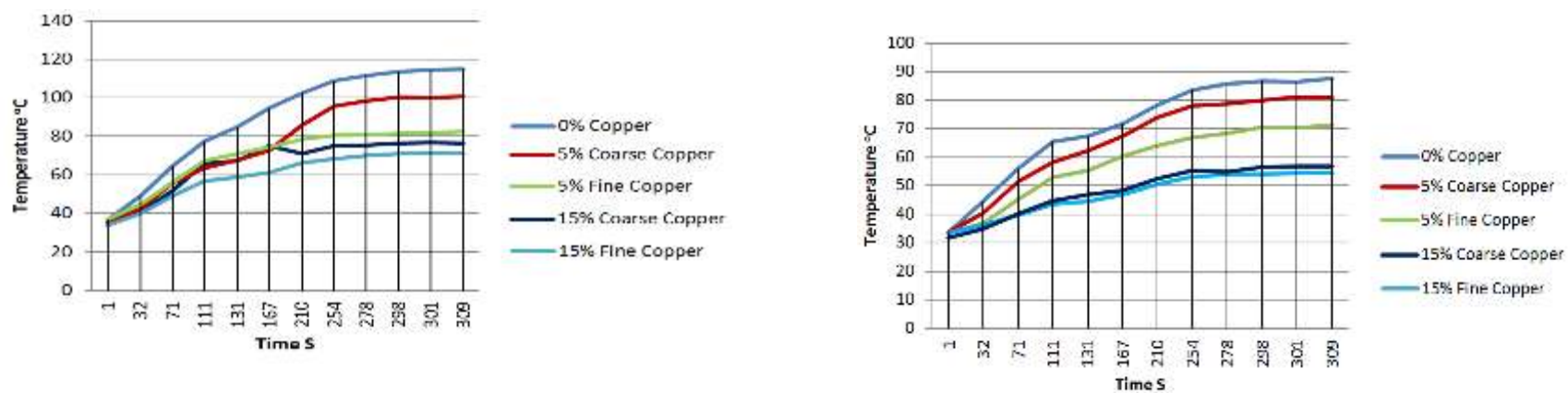

Fig 5 : Temperature raise in Natural convection at point 1 and 2
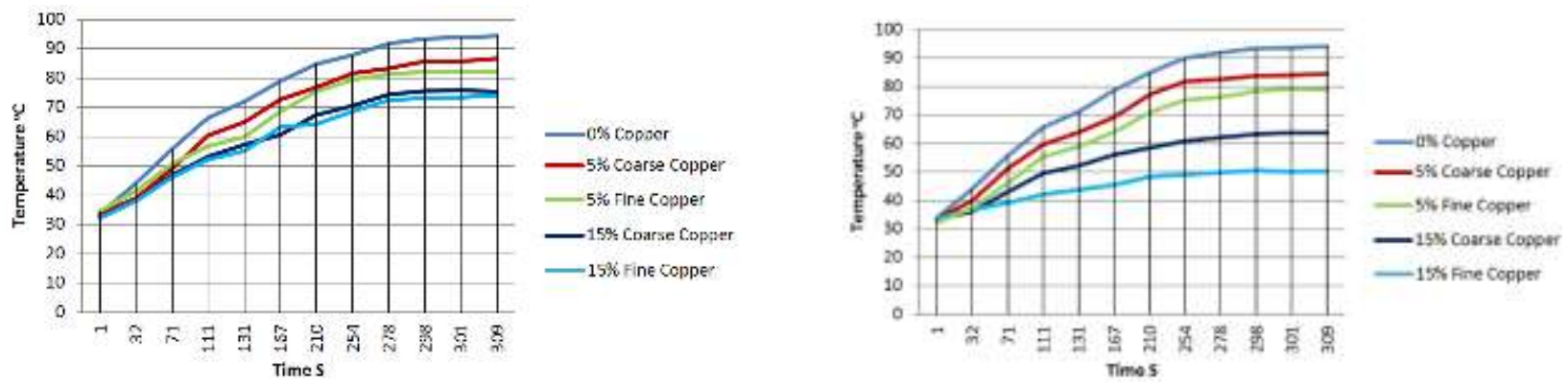

Fig 6 : Temperature raise in Natural convection at point 3 and 4

As the temperature variation differs between the points, the least temperature difference is considered the actual difference, however the least difference is not zero at any point and it is showing with the right sign. At all the four points the saturation level between $0 \%$ Copper and $5 \%$ fine copper dust mixed heat sink has at least $25^{\circ} \mathrm{C}$ at all the point. Figure 5 show the temperature raise characteristics at point one and two, and Figure 6 show the temperature raise characteristics at point 3 and 4 . The difference in temperature raise characteristics between the saturation level of coarse and fine copper dust particles is not creating a considerable difference mostly in both $5 \%$ and $15 \%$ copper added heat sinks. The difference in temperature raise between a $5 \%$ and $15 \%$ is at least $15^{\circ} \mathrm{C}$ at all the points of heat sink. Since the heat removal rate is very low compared to forced convection system of cooling, the natural convection is only for assessing the performance of the heat sink as it shows with huge saturation temperature difference with a small difference the thermal properties of the heat sink. Form the result natural convection heat transfer it is taken as the heat transfer rate increases with the addition of copper dust particles up to optimal level. 


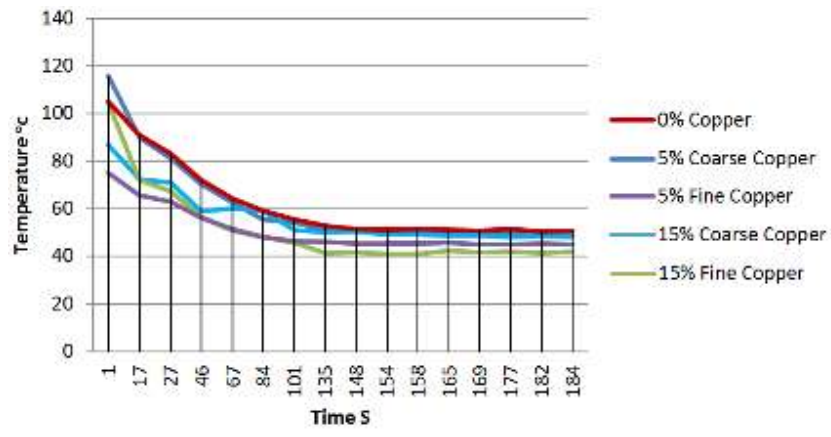

Fig 7: Temperature raise in Forced convection at point 1 and 2

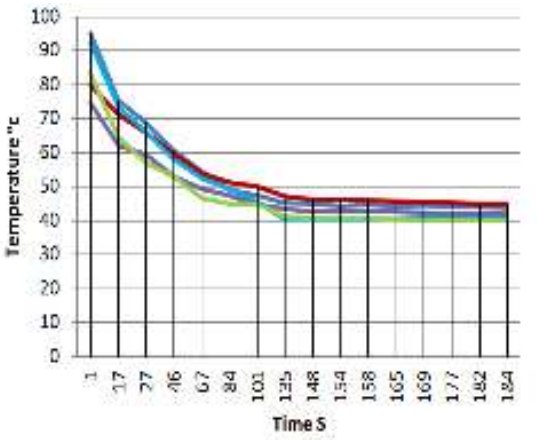

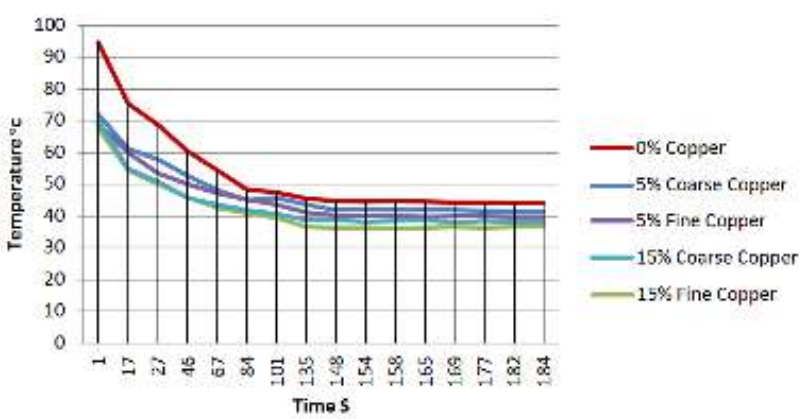

Fig 8: Temperature raise in Forced convection at point 3 and 4

Figure 7 and 8 shows tne temperature raise cnaracierısıcs at tour aitrerent poinis unaer torcea convection heat transfer. In the forced convection, the heat sink is allowed to rise to a particular temperature of $100^{\circ} \mathrm{C}$ under natural convection and the system is allowed to start the forced convection from $100^{\circ} \mathrm{C}$. The data logging takes place 10 seconds after the process starts. This $10 \mathrm{sec}$ is allowed to stabilize the thermocouple as the sudden start of airflow may create a noise signal. The response of airflow within the fins of heat sink is highly immediate. Since the airflow takes place at a speed of 35 CFM into the heat sink. The comparison of saturation temperature between the forced convection and natural convection proves that the temperature characters of heat sink remains same in both the mode of heat transfer. When the temperature difference in the natural convection reduces below $5^{\circ} \mathrm{C}$, it produces only a negligible difference in the heat transfer for forced convection system. The maximum temperature difference achieved is only of $10^{\circ} \mathrm{C}$ at all the points. This maximum difference is achieved between $0 \%$ copper and $15 \%$ fine copper Heat sinks. But under forced convection, the saturation temperature between the Fine and Coarse copper dust particles of both $5 \%$ and $15 \%$ copper Heat sinks shows only a negligible difference of $2^{\circ} \mathrm{C}$.

\section{CONCLUSION}

The thermal convection characteristics of the heat sinks with Fine and Coarse Copper particles added with aluminium, about $5 \%$ and then added with $15 \%$ of copper to pure 6063 Aluminium and the result of heat transfer characteristics is compared with pure aluminium heat sink. The geometrical characters such as fin thickness, height, and length are copied from the commercially available conventional heat sink. Simulation is carried with a commercially available CFD software called Star $\mathrm{CCM}+$. The experimental analysis is carried out to validate the results from simulation. The experiments were made under natural and forced convection system of heat transfer. Improvements are noted in Heat transfer characters in the CFD analysis. With the experimental result the saturation temperature lowers by $25^{\circ} \mathrm{C}$ in natural convection, this $25^{\circ} \mathrm{C}$ difference is achieved between 0\% copper heat sink and 15\% Fine copper dust mixed heat sink. Between Coarse and fine copper mixed heat sinks the saturation level obtained is 3 to 4 degree in natural convection where it reduces to a negligible level of temperature difference in forced convection. With the addition of $5 \%$ copper the saturation temperature reduces considerably by creating an effective heat transfer. But the saturation temperature difference is lower than that of $0 \%$ and $5 \%$ copper heat sink. So the further increase in the copper may have no effect in the heat transfer characteristics. The experiment also proves that the saturation temperature difference of $10^{\circ} \mathrm{C}$ in natural convection process will create a considerable effect in the forced convection process. This study will benefit the heat sink designers in the fabrication of heat sink for electronics cooling. 


\section{Acknowledgement}

This research is financially supported by FIST (Fund for improvement of science and technology infrastructure) programme by the Department of Science and Technology (DST) New Delhi. DST-FIST (SR/FST/College-235/2014 dated 21-11-2014) and K S Rangasamy College of Technology, Tiruchengode, India.

\section{REFERENCES}

1. Akhilesh.R, Arunn Narasimhan, Balaji.C, "Method to improve geometry for heat transfer enhancement in PCM composite heat sinks", International Journal of Heat and Mass Transfer 48 (2005) 2759-2770, April 2005.

2. Avram Bar-Cohen, Jessica R. Sheehan, Emil Rahim, "Two-Phase Thermal Transport in Microgap ChannelsTheory, Experimental Results, and Predictive Relations", Microgravity Sci. Technol. (2012) 24:1-15, September 2011.

3. Kuznetsov.V.V and Shamirzaev A. S.,"Flow Boiling Heat Transfer of Water in Microchannel Heat Sink". Journal of Engineering Thermophysics, 2012, Vol. 21, July, 2011.

4. Mohan.R and Govindarajan.P, "Expermiental and CFD analysis of heat sinks with base plate for CPU cooling,"Journal of mechanical science and technology, vol. 25(8)(2011), April 2011.

5. Mousa M. Mohamed, "Air cooling characteristics of a uniform square modules array for electronics device heat sink”, Applied Thermal Engineering 26 (2006) 486-493, September 2005.

6. Prashant Reddy.G and Navneet Gupta, "Material selection for microelectronics heat sink: An application of the Ashby approach", Journal of Material and design, July 2009.

7. Qu Z.G., Li W.Q., Wang J.L., Tao W.Q., "Passive thermal management using metal foam saturated with phase change material in a heat sink". International Communications in Heat and Mass Transfer, September 2012.

8. Venugopal Gandikota, Gerard F. Jones, Amy S. Fleischer, "Thermal performance of a carbon fiber composite material heat sink in an FC-72 Thermosyphon, Experimental Thermal and Fluid Science 34 (2010) 554-561, November 2009.

9. Wanga Q., Han X.H., Sommers A., Parkc Y., Joen C.T, Jacobi A., "A review on application of carbonaceous materials and carbon matrix composites for heat exchangers and heat sinks", international journal of refrigeration 35 (2012), September 2011.

10. Yoav Peles, Ali Kos_ar, Chandan Mishra, Chih-Jung Kuo, Brandon Schneider, "Forced convective heat transfer across a pin fin micro heat sink., International Journal of Heat and Mass Transfer 48 (2005) 3615-3627, May 2005

11. Yun Wook Hwang and Min Soo Kim, "Two-phase flow heat transfer of R-134a in microtubes". Journal of Mechanical Science and Technology 23 (2009), July 2009.

\section{Author' biography with Photo}

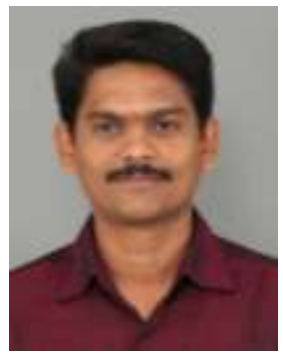

L.Arulmurugan was born in India in 1983. He is presently working as Assistant Professor(SG), Department of Mechatronics Engineering, K S Rangasamy College of Technology, Tiruchengode, India. $\mathrm{He}$ is pursuing his Ph.D in the faculty of information and communication engineering from Anna University Chennai and he holds a ME degree in Applied Electronics from Anna university, Chennai. and BE in Electronics and Communication Engineering from Bharathiar University, Coimbatore. He has published two international journals and four papers in international and national conferences. He is a life member of ISTE. His research interest is Electronics cooling system and Decision Support System.

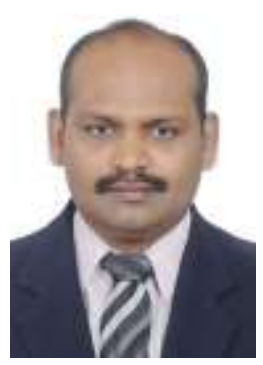

Dr. M. Ilangkumaran was born in India in 1978. He is presently working as Professor and Head, Department of Mechatronics Engineering, K.S.Rangasamy College of Technology, Tiruchengode, India. His research interest is optimization in IC engines and maintenance management. He completed his graduation in Mechanical Engineering from K.S.Rangasamy College of Technology, Tiruchengode in 1999 and Masters in Industrial Engineering from Kumaraguru College of Technology, Coimbatore in 2001. He received his Ph.D in maintenance management from Anna University, Chennai in 2010. He has published more than Forty three international and national journals and he presented six papers in national conferences. He is a life member of ISTE. 